\title{
RESEARCH PAPER \\ DEVELOPMENT OF BLACK COATING ON FILTERING MEDIA AND ITS EFFECT ON FILTER PERFORMANCE AT KPONG HEADWORKS OF GHANA
}

\author{
R. Buamah ${ }^{1}$ and A. Yakubu ${ }^{2}$ \\ ${ }^{l}$ Department of Civil Engineering, KNUST, Kumasi \\ E-mail:rbuamah@gmail.com : rabuamah.coe@knust.edu.gh \\ ${ }^{2}$ Ghana Water Company Limited, P. O. Box 5, Tamale
}

\begin{abstract}
Kpong water Treatment plant is one of the two major Water treatment plants supplying the Accra/Tema Metropolitan areas. The filtering media at Kpong water works has been observed to develop a black coating after three to four years of commissioning. This appearance results in more water than necessary being used for backwashing the filters. The source and toxicity of the black coating material as well as the possibility of it leaching into the treated water have not been determined. The main objective of this study was to characterize and investigate the development of black coating on the Kpong filtering media and its effect on the filter performance. Another focus of the study was to conduct water quality analysis of effluents from the riparian industries, and the raw water at strategic points within the study area in order to trace the source of the black coating material. The effect of the black coating on filter performance with respect to iron removal was investigated using a laboratory based batch reactor. The study showed the chemical components of the black coating of the Kpong filter media to be mainly iron, manganese, sulphates and sulphides. Other components like copper, lead, mercury occurred in trace concentrations. The blackening of the filter media at Kpong is probably due to occurrence of iron sulphates and sulphides, hydroxides and / oxides of iron and manganese ions in the raw water. The black coating has a limiting effect on the iron removal capacity of the coated (Kpong) filter media. The adsorption phenomenon on the coated media of the Volta River Authority and the fresh filter media was mainly chemisorption.
\end{abstract}

Keywords: Filter media, black coating, filter performance, iron

\section{INTRODUCTION}

The Kpong Water Treatment Plant (KWTP) is one of the two major water treatment plants supplying water to the Accra/Tema Metropolitan Areas with a population of about 3.5 mil- lion people (Brinkhoff, 2010). It has its intake located $17 \mathrm{~km}$ downstream of the Akosombo Hydro power dam. The plant consists of the two old headworks, which were commissioned in 1954 and 1966 respectively (AESC, 1975) 


\section{3}

\section{Buamah and Yakubu}

and a new headworks that was commissioned in 2014. The current production at the old and new headworks stands at 79.6 million gallons of water per day (Kpong, 2015).

It has been observed that the filtering media at the Kpong water works develops a black coating within three to four years of being in operation. This appearance creates a false impression of dirt on the filter media and therefore results in more water than necessary being used for backwashing. Another concern is the fact that the toxicity of the black coating is not known. The possibility of the coating leaching into the treated water cannot be ruled out. Some members of the general public who occasionally visit the plant express displeasure about the blackness of the media. This is against the backdrop that filtering media of water treatment plants (e.g. the VRA-WTP) which use the same raw water source but located upstream of the Volta Lake (i.e. upstream of the Akosombo dam) never become black-coated.

A number of industrial activities occur between the Akosombo hydro dam and the intake point of the Kpong WTP. These are textiles manufacturing by Akosombo Textile Limited (ATL), toilet roll manufacturing by World Cool Limited (WCL), and Banana farms by Volta River Estate Limited (VREL). To date there hasn't been any in-depth studies on the phenomenon

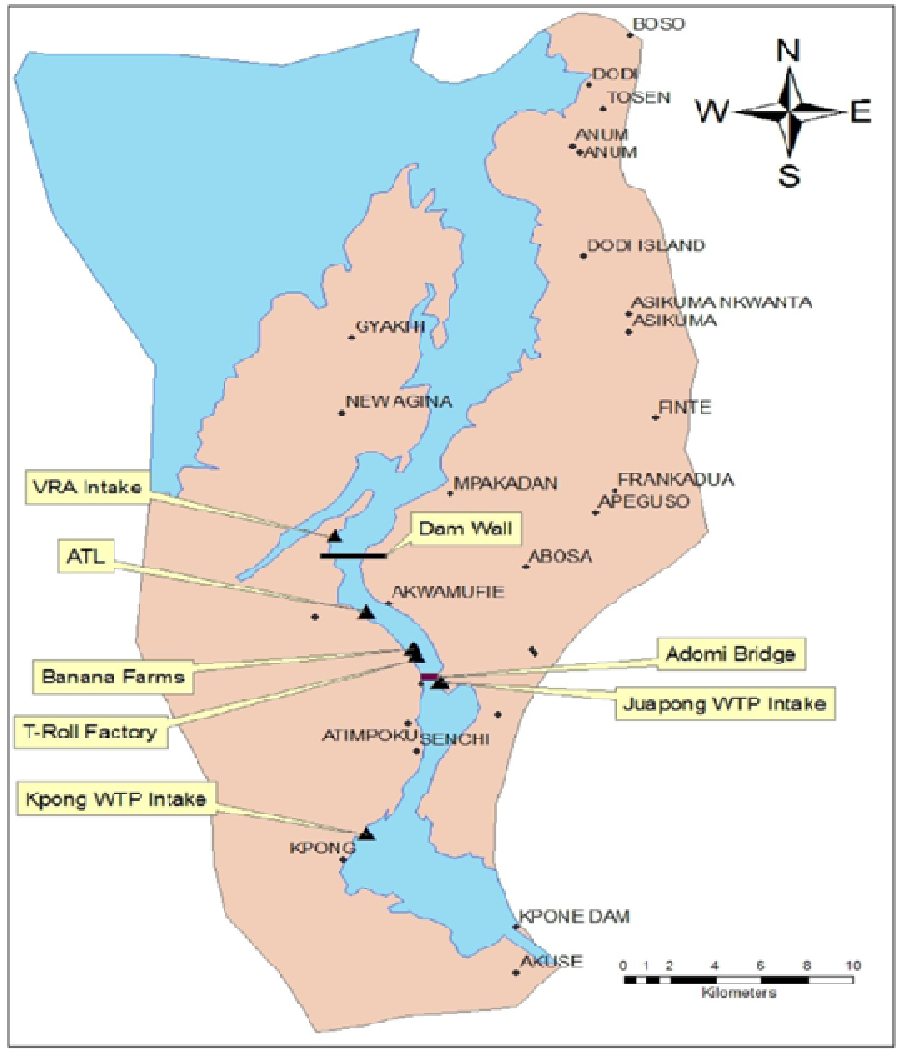

Fig. 1: Map of the study area 
at Kpong and its possible impact on the filter performance. Therefore in this study, the objectives were set as follows:

- $\quad$ To characterize the coating of KWTP filter media

- To carry out water quality analysis of the raw water and the discharges from the riparian industries occurring within the area between the Akosombo hydroelectric power dam and the intake point of the KWTP in order to trace the source of the black coating material.

- To determine the chemical components of the black coating and the effect on iron removal capacity of the KWTP filter media.

Filtration is a physical and chemical process employed for the separation of suspended and colloidal impurities from water. It is the most relied upon process for the removal of particulate material in solutions (Hudson, 1981). In filters, impurities from the raw water are removed by a combination of different processes such as adsorption, sedimentation, interception, straining, biochemical and microbial activities.

Different types of filters and filter media are used in water filtration. Filters are classified by various schemes including the type of media; the hydraulic processes; the depth of filter and the flow managent scheme (ASCE.AWWA.CSSE, 1971).

In filters generally, the removal of colloidal particles and most ions is achieved mainly through the adsorption processes. The adsorption phenomenon involves the separation of substances from one phase accompanied by its concentration on the surface of another. The adsorbing phase or surface is the adsorbent and the material concentrated is the adsorbate (Slejko, 1985).
The interactions between adsorbate and adsorbent consist of molecular forces embracing permanent dipole, induced dipole and quadruple electrostatic effects. These forces may be classified into short range forces (i.e. the chemical forces) and long range forces (i.e. the coulombic forces). The short range forces may give rise to covalent or hydrophobic bonds or hydrogen bonding or steric effect. The long range forces give rise to electrostatic attraction (Yang, 1999). Based upon these adhesive forces four principal types of adsorption have been identified: namely, ion exchange, chemical adsorption, physical adsorption and specific adsorption (Yang, 1999).

Physical adsorption is caused mainly by weak van der Waals forces and to some extent by electrostatic forces between adsorbate and adsorbent surface. The adsorbed material is not rigidly fixed to a specific site at the surface hence it is free to undergo transitional movement within the interface. Thus adsorbed material may condense and form several superimposed layers on the surface of the adsorbent. Consequently, physical adsorption is generally quite reversible (Humphrey and Keller, 1997; Seader and Henley, 1998).

Chemisorption, in contrast, involves relatively strong forces between the adsorbed molecules and the surface. As a result, the adsorbate is not free to move on the surface. Chemisorption often forms a monolayer (Sharma, 1997).

Adsorption of particles onto a filter media may depend on the type of adsorbent, the particle size, the surface area of adsorbent, and concentration of adsorbate ion present in solution (Weber, 1972). Water quality parameters such as $\mathrm{pH}$, temperature, organic matter and ionic concentration affect the adsorption efficiency of iron and manganese in raw water.

\section{Kinetic studies}

To model the kinetics of the adsorption processes of the filter media the Lagergren Pseudo First Order and the Pseudo Second Order 
models were applied. The equation below gives the linear form of Lagergren Pseudo First-

$$
\operatorname{In}\left(\mathrm{q}_{\mathrm{e}}-\mathrm{q}_{\mathrm{t}}\right)=\operatorname{Inq}_{\mathrm{e}}-\mathrm{k}_{1} \mathrm{t}
$$

Where $\mathrm{q}_{\mathrm{t}}$ is the concentration of iron II ions adsorbed on the filter media at any time ( $\mathrm{mg}$ of iron II ions/gram of filter media) and $\mathrm{k}_{1}$ is the adsorption rate constant $\left(\mathrm{min}^{-1}\right)$. A linear plot of $\ln \left(\mathrm{q}_{\mathrm{e}}-\mathrm{q}_{\mathrm{t}}\right)$ against $\mathrm{t}$ gives the slope $-\mathrm{k}_{1}$ and intercept $=\operatorname{lnq}_{\mathrm{e}}$. Below is the equation that describes the Pseudo Second-Order in its linear

$$
\mathrm{t} / \mathrm{q}_{\mathrm{t}}=1 / \mathrm{k}_{2} \mathrm{q}_{\mathrm{e}}^{2}+\left(1 / \mathrm{q}_{\mathrm{e}}\right) \mathrm{t}
$$

Where $\mathrm{k}_{2}$ is the adsorption rate constant $(\mathrm{g} / \mathrm{mg}$ $\min$ ). The $\mathrm{k}_{2}$ and $\mathrm{q}_{\mathrm{e}}$ are found from the intercept and slope of $t / \mathrm{q}_{\mathrm{t}}$ versus $\mathrm{t}$ linear plot such that $\mathrm{q}_{\mathrm{e}}$ $=1 /$ slope and $\mathrm{k}_{2}=$ slope $^{2}$ /intercept.

\section{Sand coating with iron}

Cox (1964) reported that filters could serve as contact beds following aeration where catalytic action of previously precipitated iron oxides facilitate the oxidation of iron. This method is applicable to situations where the raw water contains only iron and no organics. Ghosh et al., (1996), noted that, filter media with coats of iron precipitates, were more effective in iron removal than new, clean filters. The oxidation of iron (II) results in formation of hydroxides that can adsorb onto previously deposited iron (III) hydroxide. The newly iron (III) hydroxide formed could either be flocs or surface coatings on the filter media. This kind of mechanism is successful only if pre-oxidation before filtration is avoided (Sharma et al., 2002).

\section{Black coloured compounds}

In sand filters, blackening of the sand grains can occur if any of the following compounds occur in the raw water or are synthesized during the purification unit processes preceding the filtration. The compounds include: iron (II) oxide, iron (II) sulphides, iron (III) sulphide, copper (II) sulphide, copper (II) oxide, mercuric (II) sulphide and lead sulphide.
Iron (II) oxide (FeO) is a black solid which is insoluble in water. Iron combines with the nonmetallic elements such as oxygen, nitrogen, the halogens, sulphur and carbon. It reacts with water to form rust, $\mathrm{Fe}_{2} \mathrm{O}_{3} \cdot \mathrm{xH}_{2} \mathrm{O}$, and with steam to form iron III oxide, $\mathrm{Fe}_{3} \mathrm{O}_{4}$, which is magnetic (Brown, 1985).

Iron sulphide, $(\mathrm{FeS})$ can be precipitated from alkaline solutions of iron (II) salts. It is a black, insoluble solid which reacts with acids to give hydrogen sulphide. Like iron (II) oxide it is non -stoichiometric, ranging in composition from $\mathrm{Fe}_{0.86} \mathrm{~S}$ to $\mathrm{Fe}_{0.89} \mathrm{~S}$ (Brown, 1985).

Dry hydrogen sulphide will react with hydrated iron (III) oxide to form the sulphide as a black solid. The sulphide readily decomposes into iron (II) sulphide (FeS) and iron (II) disulphide $\left(\mathrm{FeS}_{2}\right)$ (Brown, 1985).

Copper (II) sulphide (CuS) can be produced by passing hydrogen sulphide into an acidic solution of a copper (II) salt. CuS slowly oxidises in moist air to the sulphate (Brown, 1985).

Copper (II) oxide is a black, insoluble covalent solid normally made by heating the copper metal in air or oxygen, or by heating the nitrate or carbonate (Brown, 1985).

Another black compound, mercuric (II) sulphide $(\mathrm{HgS})$ is virtually insoluble in water. $\mathrm{HgS}$ is dimorphic with two crystal forms; red cinnabar (alpha $\mathrm{HgS}$ ) and black metacinnabar (beta $\mathrm{HgS}$ ). A reaction of aqueous solutions of lead and sulphide produce black insoluble lead sulphide (PbS) (Ramsden, 1990).

\section{MATERIALS AND METHODS}

Chemical composition of the black coating Chemical analysis of KWTP and VRA-WTP filter media

With the objective of tracing the source of the black coating material, filter media of the KWTP and VRA-WTP (located 400 metres upstream of the hydro dam and $17.4 \mathrm{~km}$ apart from the KWTP) were characterized. The 
KWTP is located $17 \mathrm{~km}$ downstream of the hydro dam (Fig. 1). Both the KWTP and the VRA-WTP use similar water treatment schemes and are fed by the same raw water source. To determine the composition of the coating on the KWTP and VRA-WTP filter media, one gram samples of filter media were taken from each of the filter beds at Kpong and VRA-WTP. The samples were placed in round bottom flasks containing $100 \mathrm{ml}$ of $18.5 \% \mathrm{HCl}$ and allowed to stay overnight. The solutions were digested by heating on a hot plate for about 1 hour to ensure complete dissolution of the coating material (APHA, 2005). The solutions were then analyzed for the following metals and non-metals: manganese, copper, lead, zinc, mercury and sulphates and sulphides. For the metallic ions determination the Buck Scientific atomic absorption spectrophotometer VGP 210 was used. The sulphates and sulphides were assayed for using the Hach spectrometer DR 2010 with appropriate reagent powder pillows - sulphaver 4 .

The physical characteristics like particle size, uniformity coefficient, porosity etc. of the filter media of both Kpong and VRA WTPs were determined using sieve analysis. (Fig. 2).
Tracing the source of the black coating material

Water quality analysis of effluent and ambient water

In order to trace the source of the black coating material, the following riparian industries located between the VRA WTP and Kpong WTP were selected for sampling: Akosombo Textiles Ltd, Volta river Estate Ltd (Banana farms), World Cool Ltd (T. roll factory). At each industry, the raw water from the Volta River was sampled at a distance of about 200 meters upstream of the point of discharge of the effluent water. The raw water was again sampled at a distance of about 200 meters downstream of the point of discharge of the effluent water. In addition, samples of the effluent being discharged into the river were also taken. Each sample was analysed for the following parameters: pH, Colour, Turbidity, Dissolved oxygen, Copper, Mercury, Iron, Manganese, Sulphates, Sulphides, Conductivity and Lead.

The $\mathrm{pH}$ and colour of samples were determined using WTW $323 \mathrm{pH}$ meter and LovibondNesslerisser with a colour disc respectively. The dissolved oxygen content and conductivity were determined using WTWOxi 340 Oxy-

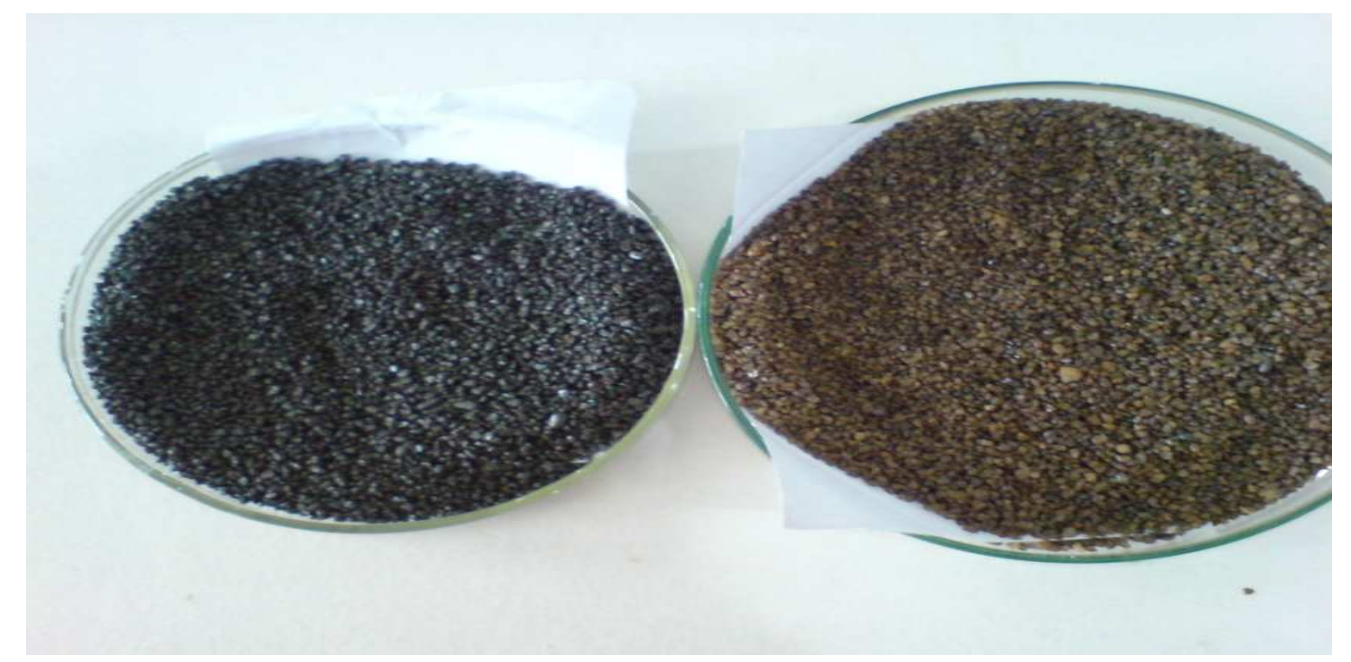

Fig. 2: Left- Kpong filter media (black) ; Right-VRA filter media (Light brown) 


\section{7}

\section{Buamah and Yakubu}

gen meter and WTW Cond 3210 handheld conductivity meter respectively. The sulphates and sulphides were assayed for using the Hach spectrometer DR 2010 with appropriate reagent powder pillows - Sulphaver 4 (specifically for sulphates) and methylene method (for sulphides). The Buck Scientific Atomic Absorption spectrophotometer VGP 210 was used for the iron and manganese determinations. Sampling was done once in a month for 5 consecutive months and the average results obtained were plotted as bar charts.

\section{Laboratory scale batch experiments}

The adsorptive performance of the four filter media, i.e. KWTP filter media, the de-coated KWTP filter media, the VRA-WTP filter media and then a fresh filter media from Dakyebi Company Limited were investigated using batch reactor experiments. The Dakyebi company limited supplies fresh filter media to the KWTP to be used in their filters. The fresh filter media, coated and de-coated KWTP filter media and the VRA-WTP filter media were washed separately with de-mineralised water and dried at room temperature for 24 hours before being used in the batch experiments.

\section{Batch experimental procedure}

A two litres batch reactor was filled with 1.5litres of de-mineralized water and dosed with
$0.045 \mathrm{~g} / \mathrm{l}$ of $\mathrm{NaHCO}_{3}, 0.017 \mathrm{~g} / \mathrm{l}$ of $\mathrm{MgSO}_{4}$, and $0.017 \mathrm{~g} / \mathrm{l}$ of $\mathrm{CaCl}_{2}$ to prepare a solution simulating the conditions that prevails in the raw water (i.e. the Volta lake) abstracted by the KWTP for treatment. The top cover of the reactor is equipped with ports for $\mathrm{pH}$ meter and oximeter electrodes (Fig. 3). The content of the reactor was stirred continuously with a mechanical stirrer at a rate of 100rpm. Nitrogen gas was infused into the solution till anaerobic condition was obtained. The $\mathrm{pH}$ of the solution was adjusted by infusing carbon dioxide gas to 6.9 \pm 0.1 ( $\mathrm{pH}$ of the Volta lake). Iron was then dosed to obtain a $0.2 \mathrm{mgFe}^{2+} / 1$ solution; and stirred continuously for 15 minutes to ensure complete mixing.

Fifteen millilitre of the solution was fetched from the reactor and immediately acidified with hydrochloric acid (time zero sample). This was followed immediately by the addition of $1.0 \mathrm{~g}$ of the coated filter media. Water samples $(10 \mathrm{ml})$ of the solution were withdrawn at:

$15 \mathrm{~min}, 30 \mathrm{~min}, 1 \mathrm{hr}, 2 \mathrm{hr}, 4 \mathrm{hr}, 6 \mathrm{hr}, 8 \mathrm{hr}$ and $12 \mathrm{~h}$; acidified with hydrochloric acid and their respective iron (II) concentration determined using Buick Scientific Atomic Absorption Spectrophotometer VGP 210. The experiment was repeated for the de-coated KWTP filter media and the VRA-WTP filter media.

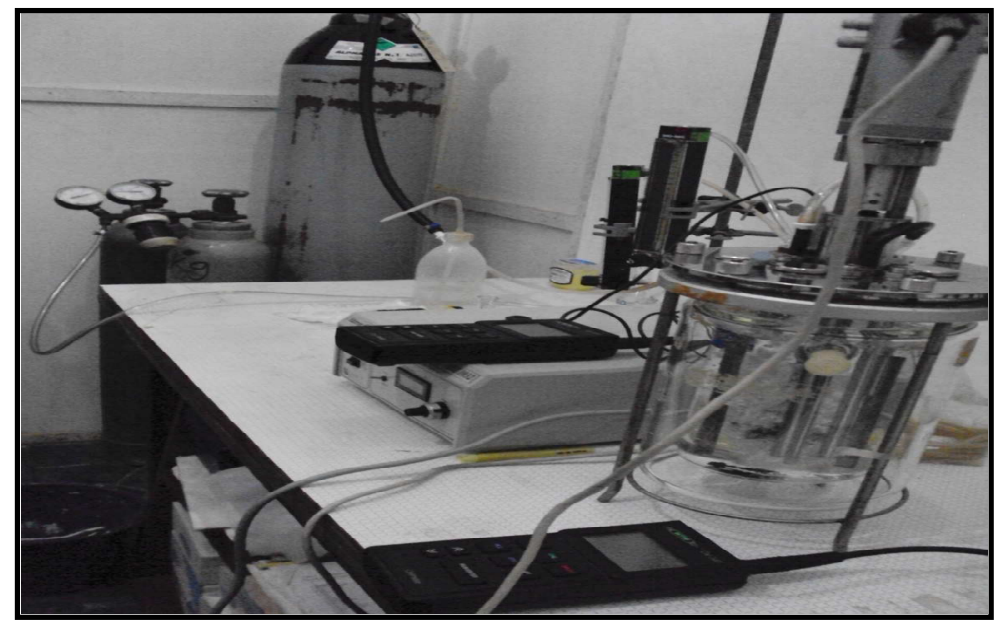

Fig. 3: Batch experiment set up 
RESULTS AND DISCUSSION

Chemical composition of the black coating

Table 1 below shows the average values of the constituents of the outer coating of the various filter media analysed and their relative occurrence at the VRA WTP and the Kpong WTP. All the ions analysed occurred in higher concentrations in the Kpong filter media coating than in the VRA WTP filter media.

The ions shown on Table 1 are those capable of giving rise to black colouration or possible black coating or deposits on a media. From the results on Table 1 , the concentration of the various ions generally is higher on the KWTP filter media than the VRA-WTP filter media; this could be an indication that, there may be sources of these contaminants other than the raw water from the Volta Lake. Thus there was the need to analyse the discharges from the riparian industries. Iron and manganese are the cations in appreciably and relatively higher concentrations and therefore likely to be the culprit contaminants for the black coating. With the higher concentration of sulphates recorded in the coating material, it can be inferred that the sulphide interacts with the iron or the manganese to get it oxidized to the sulphate. The latter reaction could be catalysed by the iron and/or manganese oxides which are very likely to be the form in which the iron or manganese exist. Iron oxide and manganese oxides are known potential catalyst (Buamah et al., 2009).

\section{Water quality parameters analysed}

The results of the water quality analyses on samples taken from riparian industries have been showcased in Figs 4 to 13. The analyses were carried out on the upstream water samples (i.e. influent water for industries), the effluent water samples and the downstream water samples. The Environmental Protection Agency (EPA) and Water Resources Commission (WRC) standard values for the various parameters have been indicated.

\section{pH}

$\mathrm{pH}$ plays a vital role in the redox reaction of metals and non- metals. In Fig. 4, the $\mathrm{pH}$ values of most of the effluents were about the same as the raw water. At ATL, the $\mathrm{pH}$ of 9.2 obtained was higher than Environmental Protection Agency Standards for effluent discharge into natural waters. This could be attributed to the use of caustic soda to reclaim wax from their waste water. This $\mathrm{pH}$ is conducive for the formation of manganese IV oxide. If $\mathrm{Mn}^{2+}$ were to be present in the effluent, it would readily be oxidized to $\mathrm{Mn}^{4+}$, which is a black insoluble solid. This when discharged into the raw water could eventually be deposited on the filter me-

Table 1: Results of analyses of filter media coating

\begin{tabular}{lccc}
\hline Parameter & VRA WTP $(\mathbf{m g} / \mathbf{g})$ & Kpong WTP $(\mathbf{m g} / \mathbf{g})$ & Increasing factor \\
\hline Iron & 2.71 & 5.96 & 2 times \\
Manganese & 0.12 & 2.06 & 17 times \\
Copper & 0.12 & 0.32 & 3 times \\
Zinc & 0.002 & 0.02 & 10 times \\
Mercury & 0.00001 & 0.00024 & 24 times \\
Lead & 0.02 & 0.03 & - \\
Sulphide & 0.00010 & 0.0005 & 5 times \\
Sulphate & 0.00704 & 0.00798 & - \\
\hline
\end{tabular}


dia at Kpong which uses the same raw water source for treatment. However the vast volumes of water of the Volta Lake occurring within the stretch of area from the point of discharge to the intake point of the KWTP may reduce the effect of the discharge. That notwithstanding, the possibility of the discharge contributing to the black coating cannot be ruled out. The volumes of the ATL discharges into the Volta
Lake must be critically considered in tracing the source of the black coating.

\section{Colour}

Colour of water can be due to organic and inorganic compounds present in it. The colours of the effluents were higher than the raw water at all the effluent discharge point of the riparian industries ( Fig. 5A). This meant that all the

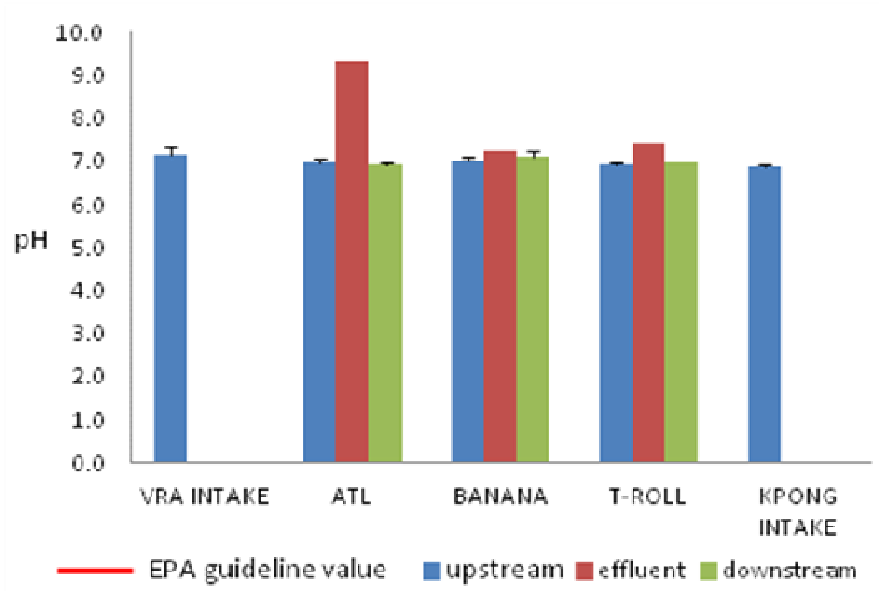

Fig. 4: pH of the raw water and discharges of the riparian industries

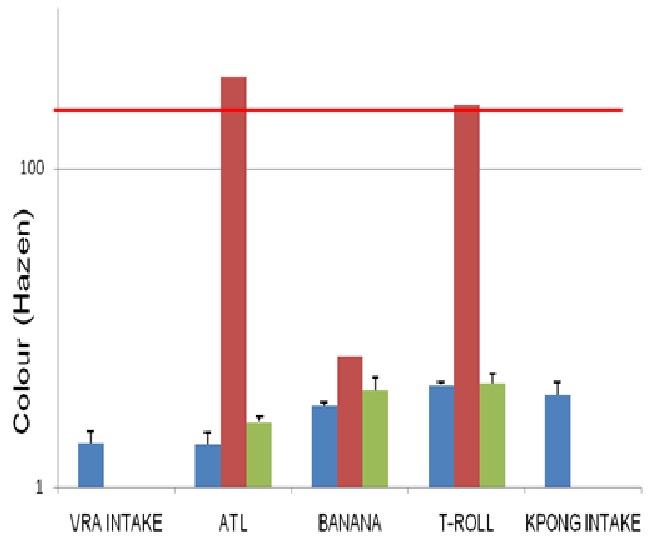

A - EPA $\backsim$ upstream $\llbracket$ effluent $\llbracket$ downstream

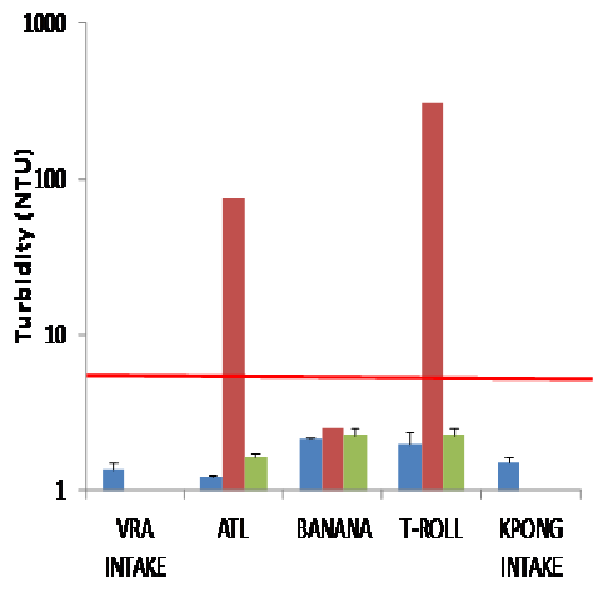

B

Fig. 5: Colour (A) and Turbidity (B) of the raw water and discharges of the riparian industries 
industries contributed some level of colour to the raw water. At ATL, colour was far above the 300 Hazen units, which is the Environmental Protection Agency (EPA) Standards for effluent discharge into natural waters. This could be attributed to the dye stuff in the effluent. This when discharged into the raw water could gradually impart colour on the raw water, as shown in Fig. 5A by the gradual increase of colour of the raw water from VRA intake to Kpong intake.

The colour of the effluent from the Banana was below the EPA Standard. At the toilet roll factory, the effluent colour also exceeded the EPA Standards. This could be due to dissolved lithographic matter and wastepaper dissolved in the water.

\section{Turbidity}

Turbidity of water is due to the presence of particulate matter (e.g. precipitates of metals and non metals, colloidal solids etc.) in the water. Results of Turbidity measurement in Fig. 5B showed a similar pattern as colour. The effluents had higher values of turbidity than the raw water at all the effluent discharge points of the riparian industries. At ATL and the Toilet roll factory, turbidity values were above EPA Standards of 75NTU for effluent discharge into natural waters. It means that these factories discharge particulate matter into the river, which may be carried along gradually onto the Kpong filters which use the same raw water source for treatment.

\section{Conductivity}

Conductivity measures the amount of dissolved ions in the water. The higher the conductivity level, the higher the amount of dissolved ions and vice-versa. Once again the effluent from the ATL had the highest conductivity (above the EPA Standards) followed by the effluent from the Toilet roll factory (Fig. 6).

\section{Iron and Manganese}

From Figs.7A and 7B, it is noted that the effluent from ATL was a major contributor of both iron and manganese to the raw water. The ATL effluent iron concentration was far in excess of the upstream and downstream values. With the prevailing $\mathrm{pH}$ of 7 , in the Volta Lake, the dis-

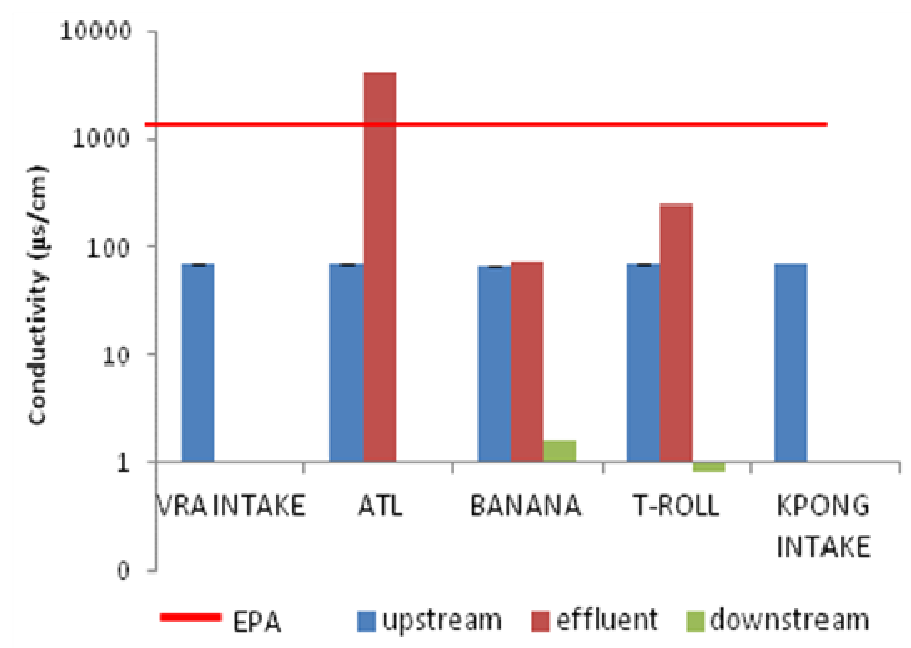

Fig. 6: Conductivity of the raw water and discharges of the riparian industries 
charged iron will exist as $\mathrm{Fe}^{3+}$ oxides or $\mathrm{Fe}^{3+}$ compounds. In the $\mathrm{Fe}^{3+}$ state, compounds of iron are mostly insoluble and the iron will be carried along as $\mathrm{Fe}^{3+}$ particles. Most ferrous and ferric compounds have dark colours (Ramsden, 1990). It can be inferred from the high concentration of iron discharged by ATL that the blackening may be due mostly to iron compounds, especially iron II sulphide and iron oxides. At Banana farms the effluent had slightly higher concentration of iron than its upstream and downstream values, showing some minimal contribution by the Banana farms.

With the $\mathrm{pH}$ of the discharged ATL waste being about 9 , the manganese ion is very likely to get oxidized faster especially in the presence of oxygen (Buamah et al., 2008). In view of this, manganese will be occurring mostly as particulate $\mathrm{Mn}^{4+}$ and $\mathrm{Mn}^{3+}$ (as $\mathrm{Mn}_{2} \mathrm{O}_{3}$ ) than the dissolved $\mathrm{Mn}^{2+} \cdot \mathrm{MnO}_{2}$ is a catalyst and can facilitate the oxidation of any $\mathrm{Mn}^{2+}$. This high manganese value however diminishes as the ATL waste water get mixed up with the high volumes of water in the Volta Lake.

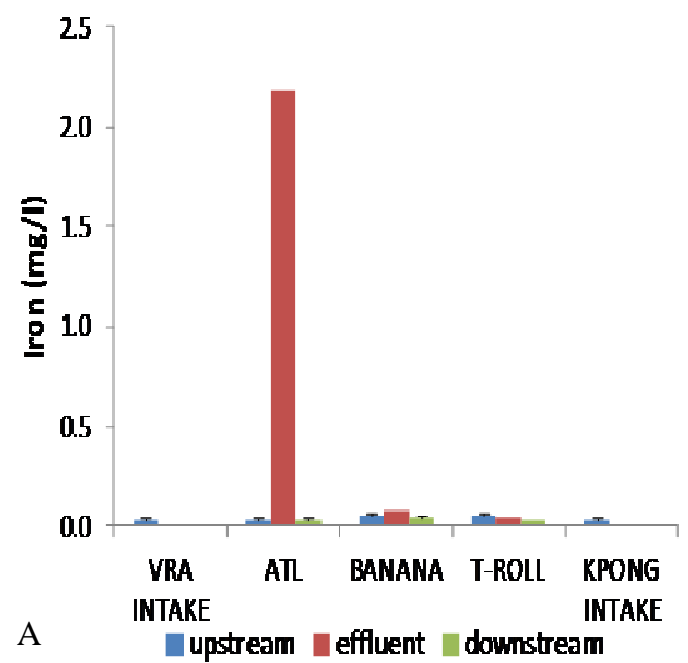

\section{Copper}

The analysis showed no significant contribution of copper by the riparian industries to the Volta Lake. With this result and the virtually insignificant concentrations of Copper, it implies that the black coating material can't be compounds of Copper.

\section{Mercury}

Mercury could be coming from other sources rather than the riparian industries because the concentration in the raw water at VRA was about the same as the concentration recorded for most of the downstream water samples (Fig. 8). Even though the concentrations were all higher than the EPA Standards, they were well within the raw water guideline for safe water. Within the Target Water Quality Range (TWQR) of $0-1 \mathrm{mg} / \mathrm{l}$ there is no health effect expected (Aquatic Ecosystems, 1996).

\section{Sulphate and Sulphide}

Sulphates can react with the iron to form Iron sulphates. This can be hydrolysed to form iron (III) hydroxide, which can form surface coat-

Fig. 7: Iron (A) and Manganese (B) concentrations of the raw water and discharges of the riparian

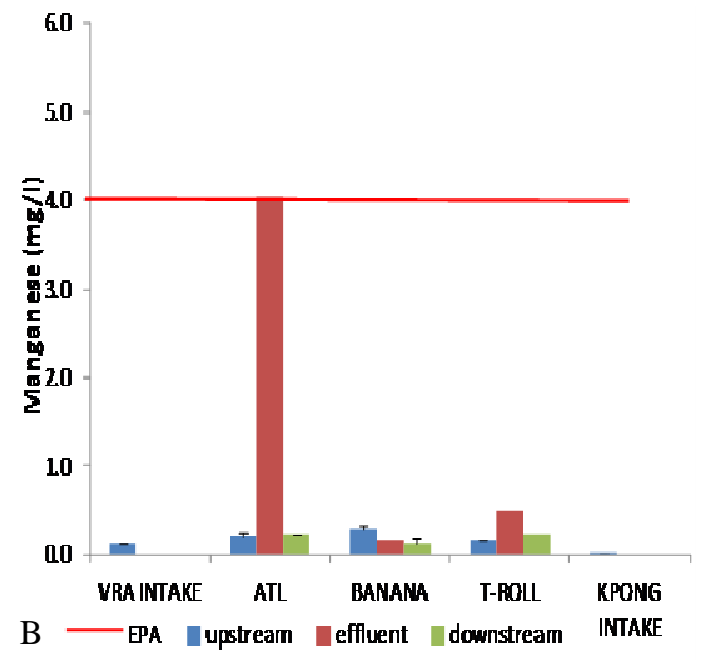


Effect of black coating on filter performance at Kpong headworks... 32

ings (Sharma et al., 2002). Fig. 9A shows ATL to be a major contributor of sulphates. This could be due to their use of sulphuric acid in neutralising the caustic soda to reclaim wax from their effluent. Toilet roll factory is also another contributor of sulphate to the raw wa- ter. Sulphuric acid is used in printing and sizing of paper in the pulp and paper industry. All the effluent concentrations of sulphate were however less than the EPA Standard value of $200 \mathrm{mg} / \mathrm{l}$. Sulphides react with iron to form iron sulphide, which is black insoluble particles.

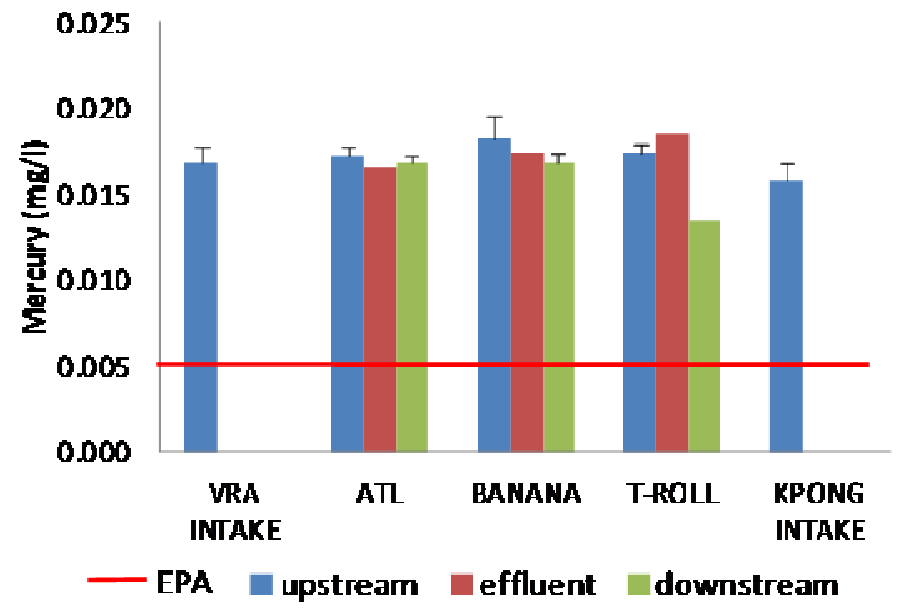

Fig. 8: Mercury concentrations of the raw water and discharges of the riparian industries
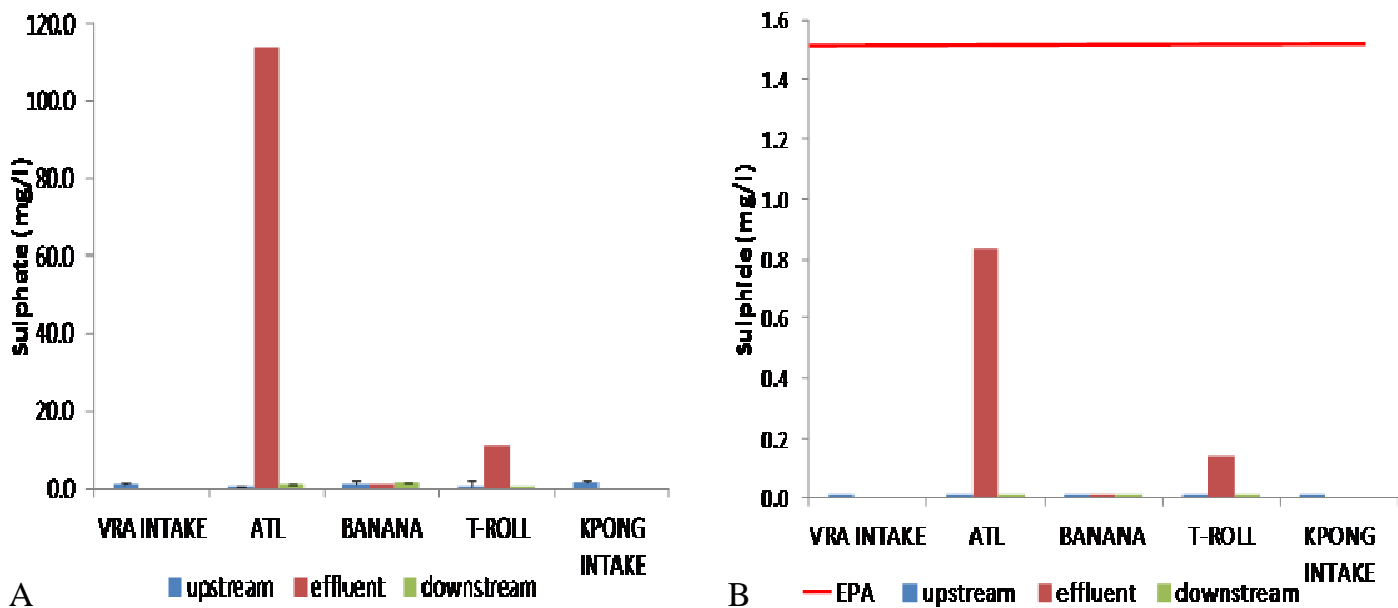

Fig. 9: Sulphate (A) and Sulphide (B) concentrations of the raw water and discharges of the riparian industries 
When discharged into the river, these particles can impart colour on the filter media at Kpong. From Fig. 9B it could be deduced that effluent from ATL is a major contributor of sulphide to the raw water

Sulphides generally are unstable and under oxidative conditions can be converted into sulphates. The high concentrations of sulphate showcased on Fig. 9A could be precursors for the formation of iron hydroxides and /or iron oxides that eventually manifest as a black coating on the sand grains. Moreover the occurrence of sulphides as a component of the black coating (Table 1) confirms the black coating material to include probably sulphides of iron, manganese and mercury.

\section{Adsorption of iron by filter media}

To investigate the contaminant removal capacity of the black coated filter media of Kpong Water Treatment Plant, laboratory scale experiments were conducted using model water dosed with $0.2 \mathrm{mg} \mathrm{Fe} \mathrm{F}^{2+} / \mathrm{L}$ at a $\mathrm{pH} 6.9$ in a reactor (Fig. 3 ). The experiment was conducted using four different filter media (i.e. black coated, de- coated, fresh and VRA WTP filter media). The experiments were conducted under anaerobic conditions so as to maintain the iron in the $\mathrm{Fe}^{2+}$ state for the monitoring of the adsorption process. In Fig. 10, the $\mathrm{Fe}^{2+}$ adsorption trends of the coated, de-coated, fresh and VRA filter media have been shown. The VRA filter media had the highest adsorption capacity. This was followed by the coated filter media, then by the fresh filter media. The de-coated filter media had the least adsorption capacity. Having been in use for about fifteen years now, the adsorption capacity of the coated filter media was expected to be higher than that of VRA filter media, which has been in use for only ten years. The higher adsorption capacity exhibited by the VRA filter media is an indication that the black coating is limiting the full adsorption potential of the coated filter media of KWTP. The VRA filter media, although fed with the same source is not coated black.

\section{First-Order and pseudo second order kinet-} ics

The Pseudo Second Order Kinetic reaction rate model adequately describes the kinetics of the

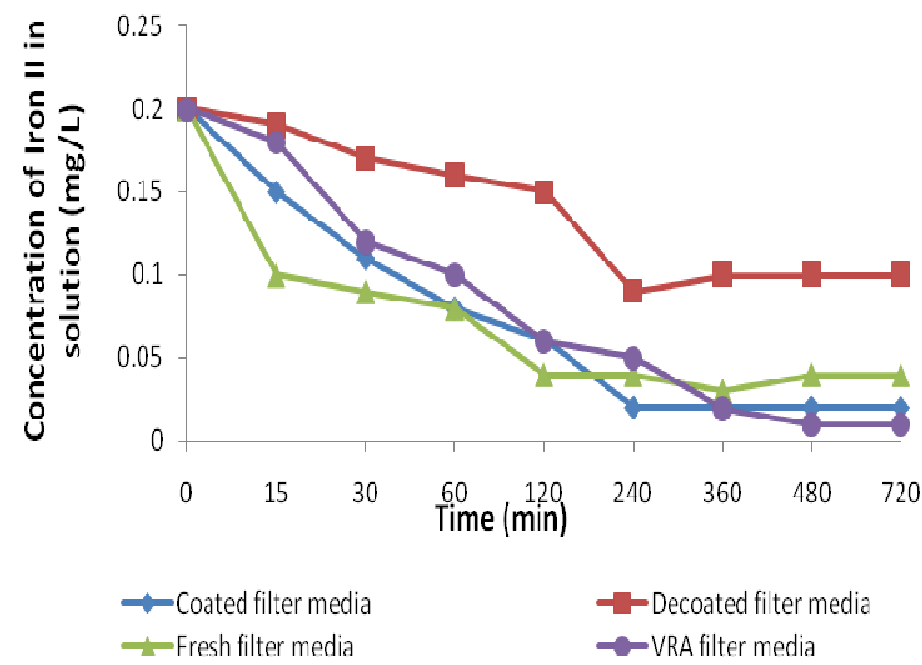

Fig. 10: Iron II adsorption onto the various filter media 
Effect of black coating on filter performance at Kpong headworks... 34

iron adsorption with a good correlation $\left(\mathrm{R}^{2}>\right.$ 0.94) for all the filter media tested except the de - coated sand (Fig. 12). According to literature (Wankasi et al, 2005), if a linear relationship is obtained for the plot of t/qt against $t$ (as in Figure 12) the sorption process may be described as chemi-sorption. Therefore with $\mathrm{R}^{2}>0.9$ obtained from this study it can be suggested that the Pseudo Second Order adsorption mechanism is predominant and that the overall manganese adsorption is likely a chemi-sorption process.

The parameters of the kinetic models (Pseudo First-Order, Pseudo Second Order) with their correspondent coefficients of determination as calculated from the slopes and intercepts of the linear plots of these models are shown in Figs. 11 and 12, and summarized in Table 2 below.

This implies that iron removal by adsorption onto the coated, the VRA and the fresh filter media is mainly chemisorption. However the higher value of $\mathrm{R}^{2}$ obtained for the VRA filter media gives indication that the black coating may be limiting the adsorption process of the coated filter media.

\section{CONCLUSIONS}

1. The chemical components of the black coating of the Kpong filter media are mainly iron, manganese, Sulphates and Sulphides. Other components like copper, lead, mercury occurred in trace concentrations.

2. Of the industrial effluents analysed, the one from ATL had the highest concentrations of iron, manganese, sulphates and sulphides. The World Cool Ltd (Toilet Roll Factory) had appreciable amounts of manganese in their effluent discharged.

3. The blackening of the filter media at Kpong is probably due to iron sulphates and sulphides of iron and manganese IV ions in the raw water. Iron oxide is likely a major contributory factor.

4. The black coating is limiting iron removal capacity of the Kpong filter media.

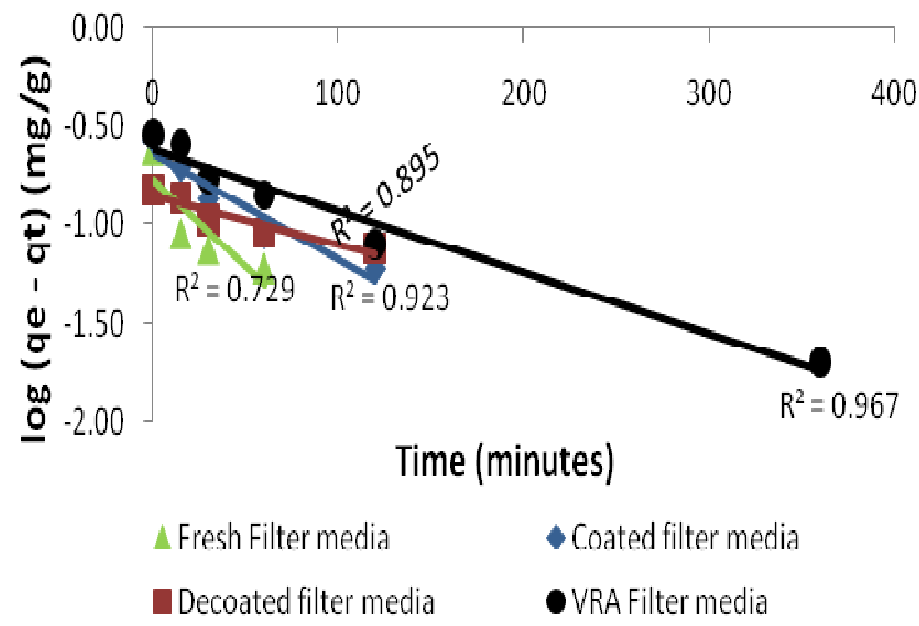

Fig. 11: Pseudo first order kinetics for filter media 


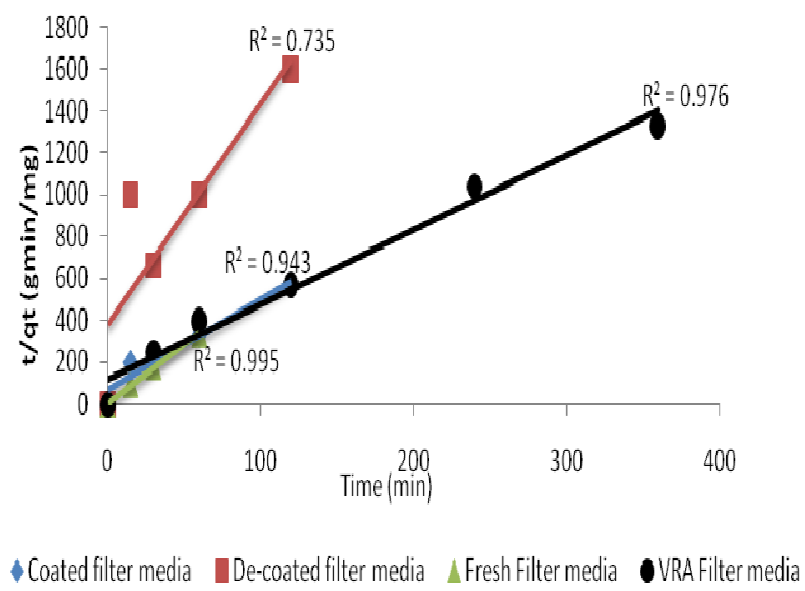

Fig. 12: Pseudo second order for filter media

Table 2: Rate constants for adsorption kinetic model of Fe (II) for tested media

\begin{tabular}{ccccc}
\hline & \multicolumn{2}{c}{ Pseudo first-order } & \multicolumn{2}{c}{ Pseudo second-order } \\
\hline Filter Media & $\mathbf{k}_{\mathbf{1}}$ & $\mathbf{R}^{\mathbf{2}}$ & $\mathbf{k}_{\mathbf{2}}$ & $\mathbf{R}^{\mathbf{2}}$ \\
Coated KWTP media & 0.005 & 0.923 & 0.25 & 0.943 \\
De-coated KWTP media & 0.002 & 0.895 & 0.29 & 0.735 \\
Fresh media & 0.008 & 0.729 & 3.1 & 0.995 \\
VRA media & 0.002 & 0.967 & 0.05 & 0.976 \\
\hline
\end{tabular}

5. The adsorption phenomenon on the coated, the fresh and the VRA filter media was mainly chemisorption.

\section{RECOMMENDATIONS}

Further works using columns must be carried out to determine the effect of the coating on the filter run time. Empirical test should be conducted on a laboratory scale to investigate how the iron and manganese IV compounds form the coating on the filter media.

\section{REFERENCES}

AESC, (1975). An Engineering Study for the Rehabilitation of Kpong Old Water Works,

\section{GWSC Report (Ghana).}

APHA, (2005). Standard methods for the examination of water and wastewater, American Public Health Association/American Water Works Association/Water Environment Federation, Washington D.C.

Aquatic Ecosystems, (1996). South African Water Quality guidelines, Vol. 7 First Edition. Department of Water Affairs and Forestry. PRETORIA, Republic of South Africa.

ASCE; AWWA and CSSE, (1971). Water Treatment Plant Design. McGraw-Hill, New 
Effect of black coating on filter performance at Kpong headworks... 36

York.

Brinkhoff, T. (2010). City Population: http:// www.citypopulation.de[Accessed: $12 / 2 / 2011]$

Brown, G. I. (1985). Introduction to Inorganic Chemistry, $2^{\text {nd }}$ edition, Longman group UK Ltd. Harlow, England.

Buamah, R., Petrusevski, B. and Schippers, J.C. (2008). Adsorptive removal of manganese (II) from the aqueous phase using iron oxide coated sand. Journal of Water Supply: Research and Technology, 57(1): 1 - 12 .

Buamah, R., Petrusevski, B., de Ridder, D., Van de Wetering, T. S. C. M. and Schippers J. C. (2009). Manganese removal in groundwater treatment: practice problems and probable solutions. Journal of Water Science and Technology: Water supply, 9 (1): 89-98.

Cox, C. R. (1964), Operation and Control of Water Treatment Processes: WHO. 209-218

Ghosh, M. M., O'Connor, J. T. and Engelbrecht, R. S. (1996). Precipitation of iron in aerated groundwater. Journal of Sanitary Engineering Division - American Society of Civil Engineering. 90(SA1) 199 - 213

Hudson, H. E. Jr. (1981). Water Clarification Process - Practical Design and Evaluation, Litton Educational Publishing Inc. 9. Van Nostrand Reinhold Company. Environmental Engineering Series, Gainesville. USA.

Humphrey, J. L. and Keller, G. E. (1997). 'Separation Process Technology'. McGrawHill, http://www.seperationprocesses.com.
[Last accessed: 12/2/2011].

Kpong, W. T. P. (2015). May - June Production Report. Kpong Water Treatment Plant, Ghana Water Company Limited.

Ramsden, E. N. (1990). A-level Chemistry, $2^{\text {nd }}$ edition. Stanley Thornes Publishers Ltd, Cheltenham, Gloucestershire, UK.

Sharma, S. K. (1997). Iron Removal in Water Treatment by Adsorption of Iron (II) onto filter media. MSc. Thesis. Unesco-IHE, Institute of Water Education Delft, Netherlands.

Sharma, S. K., Petrusevski, B. and Schippers, J. C. (2002). Characterisation of Coated Sand from Iron removal Plants. In: Adsorptive Iron Removal from Groundwater. $\mathrm{PhD}$ Thesis, Unesco-IHE, Institute for Water Education and Wageningen University. Swets and Zeitlinger B.V., Lisse.

Slejko, F. L. (1985). Adsorption Technology-A -step-by -step Approach to Process Evaluation and Application. In: Chemical Industries Series vol. 19. Slejko, F.L. (ed). Tall Oak Publishing Inc. Voorhees, New Jersey.

Seader, J. D. and Henley, E. J. (1998). 'Separation process principles' John Wiley \& Sons.USA.

Weber, W. J. (1972). Physiochemical Processes for Water Quality Control. Wiley Interscience Publication; John Wiley and Sons Inc., USA.

Yang, R. T. (1999). Gas separation by Adsorption Processes. - series on Chemical Engineering. Vol. 1, Imperial College Press, London, UK. 